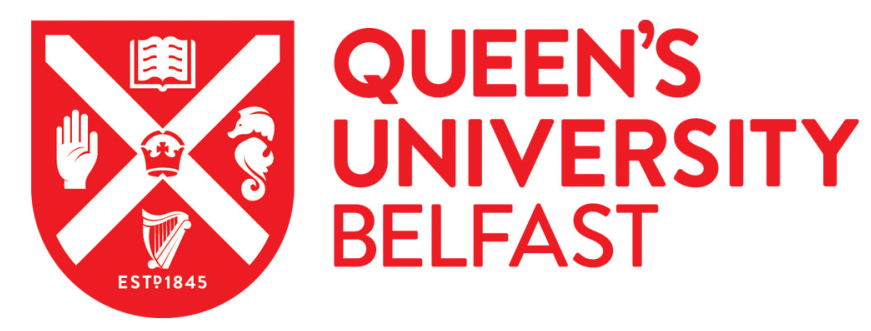

\title{
Natriuretic peptide-guided treatment for the prevention of cardiovascular events in patients without heart failure
}

Ryan, F., Ryan, C., Ledwidge, M., Mcdonald, K., Watson, C., Keane, C., \& Gallagher, J. (2018). Natriuretic peptide-guided treatment for the prevention of cardiovascular events in patients without heart failure. Cochrane Database of Systematic Reviews, 2018(4), [CD013015]. https://doi.org/10.1002/14651858.CD013015

Published in:

Cochrane Database of Systematic Reviews

Document Version:

Publisher's PDF, also known as Version of record

Queen's University Belfast - Research Portal:

Link to publication record in Queen's University Belfast Research Portal

Publisher rights

Copyright $\odot 2018$ The Cochrane Collaboration. This work is made available online in accordance with the publisher's policies. Please refer to any applicable terms of use of the publisher.

\section{General rights}

Copyright for the publications made accessible via the Queen's University Belfast Research Portal is retained by the author(s) and / or other copyright owners and it is a condition of accessing these publications that users recognise and abide by the legal requirements associated with these rights.

Take down policy

The Research Portal is Queen's institutional repository that provides access to Queen's research output. Every effort has been made to ensure that content in the Research Portal does not infringe any person's rights, or applicable UK laws. If you discover content in the Research Portal that you believe breaches copyright or violates any law, please contact openaccess@qub.ac.uk. 


\section{(E) Cochrane Library}

Cochrane Database of Systematic Reviews

\section{Natriuretic peptide-guided treatment for the prevention of cardiovascular events in patients without heart failure (Protocol)}

Ryan F, Ryan C, Ledwidge M, McDonald K, Watson C, Keane C, Gallagher J

\section{Ryan F, Ryan C, Ledwidge M, McDonald K, Watson C, Keane C, Gallagher J.}

Natriuretic peptide-guided treatment for the prevention of cardiovascular events in patients without heart failure.

Cochrane Database of Systematic Reviews 2018, Issue 4. Art. No.: CD013015.

DOI: 10.1002/14651858.CD013015.

www.cochranelibrary.com 


\section{TABLE OF CONTENTS}

HEADER . . . . . . . . . . . . . . . . . . . . . . . . . . . . . . . . . . . . . . . . 1

ABSTRACT . . . . . . . . . . . . . . . . . . . . . . . . . . . . . . . . . . . . . . . 1

BACKGROUND . . . . . . . . . . . . . . . . . . . . . . . . . . . . . . . . . . . . . . . 1

OBJECTIVES . . . . . . . . . . . . . . . . . . . . . . . . . . . . . . . . . . . . . . 2

METHODS . . . . . . . . . . . . . . . . . . . . . . . . . . . . . . . . . . . . . . .

ACKNOWLEDGEMENTS . . . . . . . . . . . . . . . . . . . . . . . . . . . . . . . . . . . . . . .

REFERENCES . . . . . . . . . . . . . . . . . . . . . . . . . . . . . . . . . . . . . . . . 6

ADDITIONAL TABLES . . . . . . . . . . . . . . . . . . . . . . . . . . . . . . . . . . . . . . . . . . . . . .

APPENDICES . . . . . . . . . . . . . . . . . . . . . . . . . . . . . . . . . . . . . . . . . . 9

CONTRIBUTIONS OF AUTHORS . . . . . . . . . . . . . . . . . . . . . . . . . . . . . . . . . . . . . . . . . .

DECLARATIONS OF INTEREST . . . . . . . . . . . . . . . . . . . . . . . . . . . . . . . . . . . 10

SOURCES OF SUPPORT . . . . . . . . . . . . . . . . . . . . . . . . . . . . . . . . . . . . . . . . . . . . . . 
[Intervention Protocol]

\title{
Natriuretic peptide-guided treatment for the prevention of cardiovascular events in patients without heart failure
}

\author{
Fiona Ryan ${ }^{1}$, Cristin Ryan ${ }^{2}$, Mark Ledwidge $^{3}$, Ken McDonald $^{4}$, Chris Watson ${ }^{5}$, Ciara Keane ${ }^{1}$, Joe Gallagher ${ }^{6}$ \\ ${ }^{1}$ The Heartbeat Trust, Dublin, Ireland. ${ }^{2}$ School of Pharmacy and Pharmaceutical Sciences, Trinity College Dublin, Dublin 2, Ireland. \\ ${ }^{3}$ The Heart Failure Unit, St Vincent's University Hospital, School of Medicine and Medical Science, Dublin, Ireland. ${ }^{4}$ The STOP-HF \\ Unit, St Vincent's Healthcare Group, Dublin, Ireland. ${ }^{5}$ Wellcome Wolfson Institute for Experimental Medicine, Queen's University \\ Belfast, Belfast, UK. ${ }^{6}$ Department of General Practice, University College Dublin, Dublin, Ireland
}

Contact address: Fiona Ryan, The Heartbeat Trust, Dublin, Ireland. fiona@heartbeat-trust.org.

Editorial group: Cochrane Heart Group.

Publication status and date: New, published in Issue 4, 2018.

Citation: Ryan F, Ryan C, Ledwidge M, McDonald K, Watson C, Keane C, Gallagher J. Natriuretic peptide-guided treatment for the prevention of cardiovascular events in patients without heart failure. Cochrane Database of Systematic Reviews 2018, Issue 4. Art. No.: CD013015. DOI: 10.1002/14651858.CD013015.

Copyright (C) 2018 The Cochrane Collaboration. Published by John Wiley \& Sons, Ltd.

\begin{abstract}
A B S T R A C T
This is a protocol for a Cochrane Review (Intervention). The objectives are as follows:

To assess the effects of natriuretic peptide (NP)-guided treatment in people with cardiovascular risk factors (without heart failure).
\end{abstract}

\section{B A C K G R O U N D}

\section{Description of the condition}

Cardiovascular disease (CVD) is the leading cause of mortality and morbidity globally, and remains the foremost cause of preventable death (Santulli 2013; WHO 2016). An estimated 17.5 million people died from CVD in 2012, representing 31\% of all global deaths (WHO 2016). In Europe, close to half of all deaths are caused by CVD (Nichols 2014), and the estimated cost to the EU economy is EUR 169 billion annually (HERC 2012).

The prevalence of CVD is set to increase further as a result of the epidemic of obesity, diabetes, hypertension and dyslipidaemia (disturbance in lipid metabolism leading to changes in plasma lipoprotein function and/or levels) (Go 2104; Piepoli 2016; Santulli 2013). One-quarter of adults aged 50 years have at least one risk factor for the development of CVD (Lloyd-Jones 2006). Accord- ing to the American Heart Association, nearly 35\% of adults in the USA have obesity (body mass index (BMI) $\geq 30 \mathrm{~kg} / \mathrm{m}^{2}$ ), almost $40 \%$ have dyslipidaemia, 33\% have hypertension, $8.3 \%$ have diabetes, and $38 \%$ have abnormal fasting glucose or pre-diabetes (Go 2104). For people free of CVD at 50 years of age, more than half of men and nearly $40 \%$ of women will develop CVD during their remaining lifespan (Lloyd-Jones 2006). Diabetes confers the highest lifetime risk for CVD of any single risk factor (Lloyd-Jones 2006), with hypertension, dyslipidaemia and obesity also identified as increased risk factors (Go 2104; Lloyd-Jones 2006; Piepoli 2016; Santulli 2013).

People with CVD who are at high cardiovascular risk need early identification (WHO 2016). Present day approaches, focusing mainly on risk factor intervention, have brought about some reduction in cardiovascular morbidity and mortality, but have fallen short of targets (Ebrahim 2011; Krogsbøll 2012).

In the setting of a worldwide increase in life expectancy and the

Natriuretic peptide-guided treatment for the prevention of cardiovascular events in patients without heart failure (Protocol)

Copyright () 2018 The Cochrane Collaboration. Published by John Wiley \& Sons, Ltd. 
continuing rise in CVD risk factors, the uniform direction of resources to a population of predominantly lower-risk patients, poses a major threat to the sustainability of healthcare systems. Evidence suggests that natriuretic peptide (NP) is effective in refining risk prediction for CVD, adding predictive power to conventional risk factors (McGrady 2013; Onodera 2012; Tarnow 2006; Wang 2004). Conventional risk indicators reflect potential for cardiovascular insult, e.g. lipids or hypertension, whereas NP is a response to established cardiovascular stress or damage.

Refining risk prediction with the aid of NP may have advantages in identifying those at highest risk of CVD over conventional risk indicators. Focusing intensive follow-up in individuals with increased NP levels would be a more sustainable use of resources.

\section{Description of the intervention}

The intervention is the measurement of plasma NP levels (BType natriuretic peptide (BNP and NT-proBNP)) in people with risk factors for CVD or established CVD (but neither known asymptomatic left ventricular systolic dysfunction nor overt heart failure at baseline), in order to predict those most at risk of CVD. NP levels that indicate an increased risk of CVD are BNP > 35 picograms per millilitre (pg/mL), or NT-proBNP > $125 \mathrm{pg} / \mathrm{mL}$, or both (as considered by the European Society of Cardiology to be the upper limit of normal in the non-acute heart failure setting) (Ponikowski 2016).

This screening is followed by NP-guided treatment for those randomised to the intervention group and standard care for the control group.

NP-guided treatment includes modification and optimisation of pharmacological therapy, diagnostic and investigation strategies, and education and lifestyle interventions based on NP levels that is supplementary to the care provided in the control group. Standard care is defined as local guideline-based care, including modification of pharmacological, education and lifestyle interventions, while not taking into account the NP level.

\section{How the intervention might work}

Modulation of traditional risk factors (e.g. hypertension, hypercholesterolaemia) have improved cardiovascular outcomes in atrisk individuals, but there is still residual risk (Ebrahim 2011; Krogsbøll 2012).

$\mathrm{BNP} / \mathrm{NT}$-proBNP is a member of the family of genetically distinct NPs synthesised and released by cardiomyocytes in response to various stimuli, including myocyte stretch due to volume expansion and pressure overload, ischaemia (reduced coronary blood supply to the heart), fibrosis and inflammation (Maeda 1998; Phelan 2012; Sabatine 2004; Yoshimura 1993). Increases in plasma BNP/ NT-proBNP concentration have diagnostic and prognostic implications in selected populations, as demonstrated initially in heart failure, and subsequently in early stage and asymptomatic disease (Eurlings 2010; Gardner 2003; Kearley 2011).

NP is superior to traditional CVD risk factors, such as hypercholesterolaemia and hypertension in identifying those at risk of heart failure (Clerico 2007), acute coronary syndrome (Glaser 2011; Scirica 2011), and coronary heart disease (Mishra 2014). New data suggest that NP screening and early intervention may prevent heart failure (Yancy 2017).

Measurement of NP level to identify those at greatest risk of cardiovascular events followed by targeted intensive risk reduction (including pharmacotherapy, diagnostic and investigation strategies and lifestyle and education interventions) may reduce the occurrence of major adverse cardiovascular events (MACE) in this population. (While the most commonly used endpoint for cardiovascular research, there is no standard definition for MACE and individual outcomes used to make this composite endpoint vary by study (Kip 2008).

\section{Why it is important to do this review}

NP-guided treatment for the optimisation of heart failure management is well established (Ponikowski 2016; Yancy 2013), and is the subject of a Cochrane Review (Kearley 2011).

Evidence for the use of NPs to identify and deliver a targeted intervention to an at-risk population is emerging, but this approach to CVD and heart failure prevention is not yet part of routine clinical care.

The 2014 Canadian Cardiovascular Society Heart Failure Management Guidelines suggest that "in individuals with risk factors for the development of heart failure, NP levels be used to implement strategies to prevent heart failure" (Moe 2015). The 2017 American Guidelines for the Management of Heart Failure, issue a 'moderate' recommendation that "for patients at risk of developing heart failure, NP-based screening followed by team-based care can be useful to prevent the development of left ventricular dysfunction (systolic or diastolic) or new-onset heart failure" (Yancy 2017). Due to the limited scientific evidence and clinical experience in this area, it is difficult for guidelines to provide a clear consensus or specific recommendations on NP screening to physicians. In this review, we would like to collate, and through meta-analysis, strengthen the existing body of evidence for this approach to CVD prevention and allow clearer recommendations to be made.

\section{O B JE C T I VES}

To assess the effects of natriuretic peptide (NP)-guided treatment in people with cardiovascular risk factors (without heart failure). 


\section{METHODS}

\section{Criteria for considering studies for this review}

\section{Types of studies}

We will include all randomised controlled trials (RCTs).

\section{Types of participants}

We will include adults ( $\geq 18$ years of age) with risk factors for the development of cardiovascular disease (CVD). We will consider the following risk factors.

- Hypertension.

- Hypercholesterolaemia.

- Obesity (BMI $\left.\geq 30 \mathrm{~kg} / \mathrm{m}^{2}\right)$.

- Metabolic syndrome.

- Vascular disease.

- Diabetes mellitus.

- Atrial fibrillation.

- Valvular heart disease.

- Elevated levels of NP, defined as BNP > $35 \mathrm{pg} / \mathrm{mL}$, or NTproBNP $>125 \mathrm{pg} / \mathrm{mL}$, or both (as considered by the European Society of Cardiology to be the upper limit of normal in the non-acute heart failure setting (Ponikowski 2016). We will include NP measured using any assay.

We will not consider lifestyle risk factors, such as sedentary lifestyle, diet, smoking and alcohol intake. We will include all healthcare settings (e.g. hospital, community).

We will exclude people with symptomatic heart failure at baseline, diagnosed by an established reference standard, such as echocardiography, cardiac magnetic resonance imaging, or specialist opinion using reference criteria, e.g. Framingham (McKee 1971), or a combination of these. At baseline we will exclude people being investigated for a possible diagnosis of symptomatic heart failure or people with any evidence of asymptomatic left ventricular systolic dysfunction (left ventricular ejection fraction $<50 \%$ ) at baseline. We will contact trialists (study authors) to request a full dataset if only a subset of eligible participants are presented. If trialists are unwilling or unable to provide additional information, we will not include the study in meta-analysis.

\section{Types of interventions}

We will include RCTs comparing NP-based screening (to identify patients at increased risk of developing a cardiac event) and subsequent NP-guided treatment with standard care. NP-guided treatment includes modification and optimisation of pharmacological therapy (as defined by the trialists), diagnostic and investigation strategies, and education and lifestyle interventions based on NP levels that is supplementary to the care provided in the control group. We will include studies that involve any element of NPguided treatment. Standard care is defined as local guideline-based care, including modification of pharmacological, education and lifestyle interventions, while not taking into account the participant's NP level.

\section{Types of outcome measures}

Reporting one or more of the outcomes listed here in the trial is not an inclusion criterion for the review. We will assess outcomes at the end of follow-up.

\section{Primary outcomes}

1. Cardiovascular mortality (as defined by trialists)

2. Cardiovascular hospitalisation (as defined by trialists)

\section{Secondary outcomes}

1. Cardiovascular mortality

2. Cardiovascular hospitalisation (all occurrences)

3. Ventricular dysfunction (as defined by trialists)

4. All-cause hospitalisations (all occurrences)

5. All-cause mortality

6. Change in NP level at the end of follow-up

\section{Search methods for identification of studies}

\section{Electronic searches}

We will identify trials through systematic searches of the following bibliographic databases.

- Cochrane Central Register of Controlled Trials

(CENTRAL) in the Cochrane Library

- MEDLINE (Ovid)

- Embase (Ovid)

- Web of Science Conference Proceedings Citation Index Science (Thomson Reuters)

We will adapt the preliminary search strategy for MEDLINE (Ovid) for use in the other databases (Appendix 1). We will apply the Cochrane sensitivity-maximising RCT filter to MEDLINE (Ovid) and adaptations of it to Embase and Web of Science (Lefebvre 2011).

We will also conduct a search of ClinicalTrials.gov ( www.ClinicalTrials.gov), the EU Clinical Trials Register ( www.clinicaltrialsregister.eu), and the World Health Organization (WHO) International Clinical Trials Registry Platform (ICTRP) Search Portal (apps.who.int/trialsearch), for ongoing or unpublished trials. 
We will search all databases from their inception to the present, and we will impose no restriction on language of publication.

\section{Searching other resources}

We will check reference lists of all primary studies and review articles for additional references. We will also examine any relevant retraction statements and errata for included studies.

\section{Data collection and analysis}

\section{Selection of studies}

Two review authors (FR, CK) will independently screen titles and abstracts for inclusion of all the potential studies we identify as a result of the search and code them as 'retrieve' (eligible or potentially eligible/unclear) or 'do not retrieve'. If there are any disagreements, a third review author will be asked to arbitrate (CR). We will retrieve the full-text study reports/publication and two review authors (FR, CK) will independently screen the full-text and identify studies for inclusion, and identify and record reasons for exclusion of the ineligible studies. We will resolve any disagreement through discussion or, if required, we will consult a third review author (CK). We will identify and exclude duplicates and collate multiple reports of the same study so that each study rather than each report is the unit of interest in the review. We will record the selection process in sufficient detail to complete a PRISMA flow diagram and 'Characteristics of excluded studies' table (Liberati 2009).

\section{Data extraction and management}

We will use a data collection form for study characteristics and outcome data which has been piloted on at least one study in the review. One review author (FR) will extract the following study characteristics from included studies.

1. Methods: study design, total duration of study, details of any 'run in' period, number of study centres and location, study setting, and date of study.

2. Participants: number of participants randomised, number of participants completing the study period, and number of participant withdrawals, mean age, age range, gender, severity of condition (as defined by the trialists), diagnostic criteria, inclusion criteria, and exclusion criteria.

3. Interventions: intervention, comparison, concomitant medications, and excluded medications.

4. Outcomes: primary and secondary outcomes specified and collected, and time points reported.

5. Notes: funding for trial, and notable conflicts of interest of trial authors.
Two review authors (FR, CK) will independently extract outcome data from included studies. Disagreements will be resolved by consensus or by involving a third review author (CR). One review author (FR) will transfer data into the Review Manager 5 (RevMan 5) file (Review Manager 2014). We will double-check that data are entered correctly by comparing the data presented in the review with the study reports. A second review author (CK) will spotcheck study characteristics for accuracy against the trial report.

\section{Assessment of risk of bias in included studies}

Two review authors (FR, CK) will independently assess risk of bias for each study using the criteria outlined in the Cochrane Handbook for Systematic Reviews of Interventions (Higgins 2017), and provide a summary judgement for each study. We will resolve any disagreements by discussion or by involving another review author (CR). We will assess the risk of bias according to the following domains.

1. Random sequence generation.

2. Allocation concealment.

3. Blinding of participants and personnel.

4. Blinding of outcome assessment.

5. Incomplete outcome data.

6. Selective outcome reporting.

7. Other bias.

We will judge each potential source of bias as high, low or unclear and provide a quote from the study report together with a justification for our judgement in the 'Risk of bias' table. We will summarise the 'Risk of bias' judgements across different studies for each of the domains listed. Where information on risk of bias relates to unpublished data or correspondence with a trialist, we will note this in the 'Risk of bias' table.

When considering treatment effects, we will take into account the risk of bias for the studies that contribute to that outcome. For our sensitivity analysis, we will exclude studies that are at high or unclear risk of bias for random sequence generation, allocation concealment, and incomplete data.

\section{Assessment of bias in conducting the review}

We will conduct the review according to this published protocol and report any deviations from it in the 'Differences between protocol and review' section of the review.

\section{Measures of treatment effect}

For dichotomous outcome data, we will calculate the effect size as risk ratios (RRs) with $95 \%$ confidence intervals (CIs).

For continuous variables, we will use standardised mean differences (SMD with 95\% CIs) if study authors use different measurement scales. If continuous outcomes are measured using the same measurement scales, we will convert data will into mean differences (MDs) and present with 95\% CIs. We will enter data 
appearing as a scale with a consistent direction of effect. Where skewed continuous outcomes are present, we will present medians and interquartile ranges.

In the event of missing summary data, e.g. missing standard deviations (SDs), we will obtain these, where possible, using calculations provided in the Cochrane Handbook for Systematic Reviews of Interventions (Higgins 2017).

\section{Unit of analysis issues}

We do not anticipate unit of analysis issues. If we identify any non-standard designs (e.g. crossover or cluster randomised trials) we will use recommendations from the Cochrane Handbook for Systematic Review of Interventions (Higgins 2017).

\section{Dealing with missing data}

Where data are missing, we will contact authors/investigators in an attempt to obtain these data and verify critical study characteristics (e.g. when a study can only be identified via the abstract). Where this is not possible, and the missing data are thought to introduce serious bias, we will explore the impact of including such studies in the overall assessment of results by a sensitivity analysis. We will extract data on both change from baseline and final value outcomes (depending on what the study has reported) if the required means and SDs are available. If a SD is not available, then we will use the standard error or CIs for group means to calculate the SD. If a SD is not available or it is not possible to calculate it, then we will exclude this from any meta-analysis.

\section{Assessment of heterogeneity}

We will assess statistical heterogeneity visually and by using the $\mathrm{I}^{2}$ statistic. We will conduct a fixed-effect meta-analysis if no heterogeneity is present, otherwise, if we identify substantial heterogeneity $\left(\mathrm{I}^{2}>50 \%\right)$ we will employ a random-effects model, provide possible interpretations by reporting the clinical heterogeneity, e.g. descriptive summary of the participants, study designs and interventions carried out in each analysis, and will explore possible causes by conducting prespecified subgroup analyses (Ryan 2016; detailed in Subgroup analysis and investigation of heterogeneity).

\section{Assessment of reporting biases}

If we are able to pool more than 10 trials, we will create and examine a funnel plot to explore possible small study biases for the primary outcomes (Sedgwick 2013).

\section{Data synthesis}

We will employ a fixed-effect meta-analysis when no substantial heterogeneity is present $\left(\mathrm{I}^{2}<50 \%\right)$, otherwise we will use a random-effects model (see Assessment of heterogeneity above). We will provide a narrative description of parameters describing clinical heterogeneity (e.g. study designs) as above.

\section{'Summary of findings' table}

We will create a 'Summary of findings' table using the following primary and secondary outcomes: cardiovascular mortality (as defined by trialists), cardiovascular hospitalisation (as defined by trialists), ventricular dysfunction (as defined by trialists), all-cause hospitalisations, all-cause mortality, and change in NP level from baseline. We will create a 'Summary of findings' table with these outcomes (see Table 1).

We will use the five GRADE considerations (study limitations, consistency of effect, imprecision, indirectness and publication bias) to assess the certainty of a body of evidence as it relates to the studies which contribute data to the meta-analyses for the prespecified outcomes. We will use methods and recommendations described in Section 8.5 and Chapter 12 of the Cochrane Handbook for Systematic Reviews of Interventions (Higgins 2017), using GRADEpro GDT software (GRADEpro GDT 2015). We will justify all decisions to downgrade or upgrade the certainty of studies using footnotes and we will make comments to aid reader's understanding of the review where necessary. Two review authors (FR, CK) will undertake this assessment independently. Disagreements will be resolved by consensus or my involving a third review author (CR).

\section{Subgroup analysis and investigation of heterogeneity}

If there are sufficient data, we will perform subgroup analyses for the primary outcome for the following.

1. Age ( $\geq 65$ years and $<65$ years).

2. Gender (NP is higher in females).

3. Diabetes mellitus (NP is higher in diabetes mellitus).

4. Obesity (BMI $\geq 30 \mathrm{~kg} / \mathrm{m}^{2}$ versus $\left.\mathrm{BMI}<30 \mathrm{~kg} / \mathrm{m}^{2}\right)$.

5. Atrial fibrillation versus non-atrial fibrillation.

6. Valvular heart disease versus non-valvular heart failure.

7. Ischaemic heart failure versus non-ischaemic heart failure.

8. NP levels at baseline to classify subgroups (BNP $35 \mathrm{pg} / \mathrm{mL}$ to $100 \mathrm{pg} / \mathrm{mL}$ and $\geq 100 \mathrm{pg} / \mathrm{mL}$; NT-proBNP $125 \mathrm{pg} / \mathrm{mL}$ to $300 \mathrm{pg} / \mathrm{mL}$ and $\geq 300 \mathrm{pg} / \mathrm{mL}$ ). The lower limit for these subgroups is derived from the European Society of Cardiology Guidelines (Ponikowski 2016), and the upper limit for these subgroups represent the cut-off points for the implementation of strategies to prevent heart failure, as specified in the 2014 Canadian Cardiovascular Society Heart Failure Management Guidelines (Moe 2015).

9. Renal function (estimated Glomerular Filtration Rate $(\mathrm{eGFR}) \geq 60 \mathrm{ml} / \mathrm{min} / 1.73 \mathrm{~m}^{2}$ or $<60 \mathrm{ml} / \mathrm{min} / 1.73 \mathrm{~m}^{2}$ as measured by the Cockcroft and Gault or Modification of Diet in Renal Disease (MDRD) formula)

Older age, female gender and diabetes are associated with higher NP levels (Raymond 2003; Wang 2002). 
We will use the primary outcome in subgroup analyses, i.e. cardiovascular mortality and cardiovascular hospitalisation.

We will use the formal statistical test for heterogeneity across subgroups based on the random-effects model to test for subgroup interactions (Borenstein 2008) and we will use caution in the interpretation of subgroup analyses, as advised in Section 9.6 of the Cochrane Handbook for Systematic Reviews of Interventions (Deeks 2017).

\section{Sensitivity analysis}

We will conduct sensitivity analyses to test the robustness of the results using the results of the 'Risk of bias' assessment. We will exclude studies that are at high or unclear risk of bias for random sequence generation, allocation concealment, and incomplete data.

\section{Reaching conclusions}

We will base our conclusions only on findings from the quantitative or narrative synthesis of included studies for this review. We will avoid making recommendations for practice and our implications for research will suggest priorities for future research and outline any remaining uncertainties in the area.

\section{R E F E R E N C E S}

\section{Additional references}

\section{Clerico 2007}

Clerico A, Fontana M, Zyw L, Passino C, Emdin M. Comparison of the diagnostic accuracy of brain natriuretic peptide (BNP) and the $\mathrm{n}$-terminal part of the propeptide of BNP immunoassays in chronic and acute heart failure: a systematic review. Clinical Chemistry 2007;53(5):813-22.

\section{Deeks 2017}

Deeks JJ, Higgins JP, Altman DG (editors) on behalf of the Cochrane Statistical Methods Group. Chapter 9: Analysing data and undertaking metaanalyses. In: Higgins JP, Churchill R, Chandler J, Cumpston MS (editors), Cochrane Handbook for Systematic Reviews of Interventions version 5.2.0 (updated June 2017), Cochrane, 2017. Available from www.training.cochrane.org/handbook.

Ebrahim 2011

Ebrahim S, Taylor F, Ward K, Beswick A, Burke M, Smith D. Multiple risk factor interventions for primary prevention of coronary heart disease. Cochrane Database of Systematic Reviews 2011, Issue 1. DOI: 10.1002/ 14651858.CD001561.pub3

Eurlings 2010

Eurlings L, van Pol P, Kok W, van Wijk S, Lodewijksvan der Bolt $\mathrm{C}$, Balk $\mathrm{A}$, et al. Management of chronic heart failure guided by individual $n$-terminal pro-b-type natriuretic peptide targets: results of the PRIMA (Can PRobrain-natriuretic peptide guided therapy of chronic heart failure IMprove heart fAilure morbidity and mortality?) study. Journal of the American College of Cardiology 2010;56 (25):2090-100.

Gardner 2003

Gardner R, Ozalp F, Murday A, Robb S, McDonagh T. Nterminal pro-brain natriuretic peptide. A new gold standard in predicting mortality in patients with advanced heart failure. European Heart Journal 2003;24:1735-43.

\section{ACKNOWLEDGEMENTS}

We would like to thank Charlene Bridges, Cochrane Information Specialist, for assistance with the search strategy.

\section{Glaser 2011}

Glaser R, Peacock WF, Wu AH, Muller R, Möckel M, Apple FS. Placental growth factor and b-type natriuretic peptide as independent predictors of risk from a multibiomarker panel in suspected acute coronary syndrome (Acute Risk and Related Outcomes assessed With cardiac biomarkers [ARROW]) study. American Journal of Cardiology 2011; 107(6):821-6.

\section{Go 2104}

Go A, Mozaffarian D, Roger V, Benjamin E, Berry J, Blaha M, et al. Heart disease and stroke statistics. 2014 update: a report from the American Heart Association. Circulation 2014;129(3):228-92.

\section{GRADEpro GDT 2015 [Computer program]}

McMaster University (developed by Evidence Prime). GRADEpro GDT. Hamilton (ON): McMaster University (developed by Evidence Prime), 2015.

\section{HERC 2012}

Health Economics Research Centre. CVD costs in Europe: the economic burden of cardiovascular disease in the enlarged European Union. www.herc.ox.ac.uk/research/ disease-cost-studies-1/studies-14/cvd-costs-in-europethe-economic-burden-of-cardiovascular-disease-in-theenlarged-european-union-1 (accessed 21 July 2016).

\section{Higgins 2017}

Higgins JP, Altman DG, Sterne JAC (editors). Chapter 8: Assessing risk of bias in included studies. In: Higgins JP, Churchill R, Chandler J, Cumpston MS (editors), Cochrane Handbook for Systematic Reviews of Interventions version 5.2.0 (updated June 2017), Cochrane, 2017. Available from www.training.cochrane.org/handbook.

\section{Kearley 2011}

Kearley K, Wright F, Tyndel S, Roberts N, Perera R, Glasziou $\mathrm{P}$, et al. B-type natriuretic peptide-guided treatment for 
heart failure. Cochrane Database of Systematic Reviews 2011, Issue 1. DOI: 10.1002/14651858.CD008966

\section{Kip 2008}

Kip KE, Hollabaugh K, Marroquin OC, Williams DO.

The problem with composite end points in cardiovascular studies: the story of major adverse cardiac events and percutaneous coronary intervention. Journal of the American College of Cardiology 2008;51(7):701-7.

\section{Krogsbøll 2012}

Krogsbøll L, Jørgensen K, Grønhøj Larsen C, Gøtzsche P. General health checks in adults for reducing morbidity and mortality from disease. Cochrane Database of Systematic Reviews 2012, Issue 10. DOI: 10.1002/ 14651858.CD009009.pub2

\section{Lefebvre 2011}

Lefebvre C, Manheimer E, Glanville J. Chapter 6: Searching for studies. In: Higgins JP, Green S, editor(s). Cochrane Handbook for Systematic Reviews of Interventions Version 5.1.0 (updated March 2011). The Cochrane Collaboration, 2011. Available from handbook.cochrane.org.

\section{Liberati 2009}

Liberati A, Altman DG, Tetzlaff J, Mulrow C, Gotzsche PC, Ioannidis JP, et al. The PRISMA statement for reporting systematic reviews and meta-analyses of studies that evaluate health care interventions: explanation and elaboration. PLoS Medicine 2009;6(7):e1000100.

\section{Lloyd-Jones 2006}

Lloyd-Jones D, Leip E, Larson M, D'Agostino R, Beiser A, Wilson P, et al. Prediction of lifetime risk for cardiovascular disease by risk factor burden at 50 years of age. Circulation 2006;133(6):791-8

\section{Maeda 1998}

Maeda K, Tsutamoto T, Wada A, Hisanaga T, Kinoshita M. Plasma brain natriuretic peptide as a biochemical marker of high left ventricular end-diastolic pressure in patients with symptomatic left ventricular dysfunction. American Heart Journal 1998 May;135(5):825-32.

\section{McGrady 2013}

McGrady M, Reid C, Shiel L, Wolfe R, Boffa U, Liew D, et al. $\mathrm{N}$-terminal b-type natriuretic peptide and the association with left ventricular diastolic function in a population at high risk of incident heart failure: results of the SCReening Evaluation of the Evolution of New-Heart Failure Study (SCREEN-HF). European Journal of Heart Failure 2013;14: 573-80.

McKee 1971

McKee AP, Castelli WP, McNamara PM, Kannel WB. The natural history of congestive heart failure: the Framingham Study. New England Journal of Medicine 1971;285(26): 1441-6.

\section{Mishra 2014}

Mishra RK, Beatty AL, Jaganath R, Regan M, Wu AHB, Whooley MA. B-type natriuretic peptides for the prediction of cardiovascular events in patients with stable coronary heart disease: the heart and soul study. Journal of the American Heart Association 2014;3(4):1-9.

Moe 2015

Moe G, Ezekowitz J, O’Meara E, Lepage S, Howlett J, Fremes S, et al. The 2014 Canadian Cardiovascular Society heart failure management guidelines focus update: anemia, biomarkers, and recent therapeutic trial implications. Canadian Journal of Cardiology 2015;31(1):3-16.

\section{Nichols 2014}

Nichols M, Townsend N, Scarborough P, Rayner M. Cardiovascular disease in Europe 2014: epidemiological update. European Heart Journal 2014;35(42):2950-9.

\section{Onodera 2012}

Onodera M, Nakamura M, Tanaka F, Takahashi T, Makita $\mathrm{S}$, Ishisone $\mathrm{T}$, et al. Plasma b-type natriuretic peptide is useful for cardiovascular risk assessment in communitybased diabetes subjects: comparison with albuminuria. International Heart Journal 2012;53(3):176-81.

\section{Phelan 2012}

Phelan D, Watson C, Martos R, Collier P, Patle A, Donnelly $\mathrm{S}$, et al. Modest elevation in BNP in asymptomatic hypertensive patients reflects sub-clinical cardiac remodeling, inflammation and extracellular matrix changes. PLoS One 2012;7(11):e49259.

\section{Piepoli 2016}

Piepoli M, Hoes A, Agewall S, Albus C, Brotons C, Catapano AL, et al. 2016 European guidelines on cardiovascular disease prevention in clinical practice. European Heart Journal 2016;37(29):2315-81.

\section{Ponikowski 2016}

Ponikowski P, Voors A, Anker S, Bueno H, Cleland J, Coats A, et al. 2016 ESC guidelines for the diagnosis and treatment of acute and chronic heart failure. European Heart Journal 14 Jul 2016;37(27):2129-200.

\section{Raymond 2003}

Raymond I, Groenning B, Hildebrandt P, Nilsson J, Baumann M, Trawinski J, et al. The influence of age, sex and other variables on the plasma level of $n$-terminal pro brain natriuretic peptide in a large sample of the general population. Heart 2003;89(7):745-51.

\section{Review Manager 2014 [Computer program]}

Nordic Cochrane Centre, The Cochrane Collaboration. Review Manager 5 (RevMan 5). Version 5.3. Copenhagen: Nordic Cochrane Centre, The Cochrane Collaboration, 2014.

\section{Ryan 2016}

Ryan R. Heterogeneity and subgroup analyses in Cochrane Consumers and Communication Group reviews: planning the analysis at protocol stage. cccrg.cochrane.org (accessed 09 April 2018).

Sabatine 2004

Sabatine M, Morrow D, de Lemos J, Omland T, Desai M, Tanasijevic M, et al. Acute changes in circulating natriuretic peptide levels in relation to myocardial ischemia. Journal of the American College of Cardiology 2004;44(10):1988-95. 


\section{Santulli 2013}

Santulli G. Epidemiology of cardiovascular disease in the 21st century: Updated numbers and updated facts. Journal of Cardiovascular Disease 2013;1(1):2326-3121.

Scirica 2011

Scirica BM, Sabatine MS, Jarolim P, Murphy SA, de Lemos JL, Braunwald E, et al. Assessment of multiple cardiac biomarkers in non-ST-segment elevation acute coronary syndromes: observations from the MERLIN-TIMI 36 Trial. European Heart Journal 2011;32(6):697-705.

\section{Sedgwick 2013}

Sedgwick, P. Selection bias versus allocation bias. British Medical Journal 2013;346:f1342.

\section{Tarnow 2006}

Tarnow L, Gall M, Hansen B, Hovind P, Parving H. Plasma n-terminal pro-b-type natriuretic peptide and mortality in type 2 diabetes. Diabetologia 2006;49:2256-326.

\section{Wang 2002}

Wang T, Larson M, Levy D, Leip E, Benjamin E, Wilson P, et al. Impact of age and sex on plasma natriuretic peptide levels in healthy adults. American Journal of Cardiology 2002;90(3):254-8.

\section{Wang 2004}

Wang T, Larson M, Levy D, Benjamin E, Leip E, Omland $\mathrm{T}$, et al. Plasma natriuretic peptide levels and the risk of cardiovascular events and death. New England Journal of Medicine 2004;350(7):655-63.

\section{WHO 2016}

World Health Organization. Cardiovascular diseases fact sheet. www.who.int/mediacentre/factsheets/fs317/en/ (accessed 21 July 2016).

Yancy 2013

Yancy CW, Jessup M, Bozkurt B, Butler J, Casey DE Jr, Drazner MH, et al. $2013 \mathrm{ACCF} / \mathrm{AHA}$ guideline for the management of heart failure: a report of the American College of Cardiology Foundation/American Heart Association Task Force on practice guidelines. Circulation 2013;128(16):240-327.

Yancy 2017

Yancy CW, Jessup M, Bozkurt B, Butler J, Casey DE, Colvin MM, et al. ACC/AHA/HFSA focused update of the 2013 ACCF/AHA guideline for the management of heart failure: a report of the American College of Cardiology/ American Heart Association Task Force on Clinical Practice Guidelines and the Heart Failure Society of America. Circulation 2017;136:137-61.

\section{Yoshimura 1993}

Yoshimura M, Yasue H, Okumura K, Ogawa H, Jougasaki M, Mukoyama M, et al. Different secretion patterns of atrial natriuretic peptide and brain natriuretic peptide in patients with congestive heart failure. Circulation 1993;87: 464-9.

* Indicates the major publication for the study

\section{ADDITIONAL TABLES}

Table 1. 'Summary of findings' table - draft

Natriuretic peptide-based screening and subsequent NP-guided treatment compared to standard care for prevention of cardiovascular mortality and hospitalisation in those with cardiovascular risk factors

Patient or population: people with cardiovascular risk factors

Setting: any

Intervention: natriuretic peptide-based screening and subsequent NP-guided treatment

Comparison: standard care

\begin{tabular}{|c|c|c|c|c|c|c|}
\hline \multirow[t]{2}{*}{ Outcomes } & \multicolumn{2}{|c|}{$\begin{array}{l}\text { Anticipated absolute effects* } \\
(95 \% \text { CI })\end{array}$} & \multirow[t]{2}{*}{$\begin{array}{l}\text { Relative effect } \\
(95 \% \mathrm{CI})\end{array}$} & \multirow{2}{*}{$\begin{array}{l}\text { № } \\
\text { participants } \\
\text { (studies) }\end{array}$} & \multirow{2}{*}{$\begin{array}{l}\text { Certainty of the } \\
\text { evidence } \\
\text { (GRADE) }\end{array}$} & \multirow[t]{2}{*}{ Comments } \\
\hline & $\begin{array}{l}\text { Risk with stan- } \\
\text { dard care }\end{array}$ & $\begin{array}{l}\text { Risk with NP- } \\
\text { based screening } \\
\text { and subsequent } \\
\text { NP-guided } \\
\text { treatment }\end{array}$ & & & & \\
\hline
\end{tabular}


Table 1. 'Summary of findings' table - draft (Continued)

\section{Cardiovascular} mortality

Cardiovascular hospitalisation

Ventricular dysfunction

All-cause hospitalisations (all occurrences)

All-cause mortality

NP level at the end of follow-up

${ }^{*}$ The risk in the intervention group (and its $95 \%$ confidence interval) is based on the assumed risk in the comparison group and the relative effect of the intervention (and its $95 \% \mathrm{CI}$ ).

CI: confidence interval; RR: risk ratio; OR: odds ratio;

\section{GRADE Working Group grades of evidence}

High-certainty: we are very confident that the true effect lies close to that of the estimate of the effect

Moderate-certainty: we are moderately confident in the effect estimate; the true effect is likely to be close to the estimate of the effect, but there is a possibility that it is substantially different

Low-certainty: our confidence in the effect estimate is limited; the true effect may be substantially different from the estimate of the effect

Very low-certainty: we have very little confidence in the effect estimate; the true effect is likely to be substantially different from the estimate of effect 


\section{A P P E N D I C E S}

\section{Appendix I. Preliminary MEDLINE (Ovid) search strategy}

1 Natriuretic Peptide, Brain/

2 (Natriuretic peptide* adj3 (B or brain or pro-brain or b-type or type-b or ventricular)).tw.

3 BNP*.tw.

4 NT-proBNP.tw.

5 NTproBNP.tw.

$6 \mathrm{BNPT}^{*} . \mathrm{tw}$.

7 probnp*.tw.

8 pro-bnp*.tw.

9 natriuretic factor.tw.

101 or 2 or 3 or 4 or 5 or 6 or 7 or 8 or 9

11 randomized controlled trial.pt.

12 controlled clinical trial.pt.

13 randomized.ab.

14 placebo.ab.

15 clinical trials as topic.sh.

16 randomly.ab.

17 trial.ti.

1811 or 12 or 13 or 14 or 15 or 16 or 17

19 exp animals/ not humans.sh.

2018 not 19

2110 and 20

\section{CONTRIBUTIONSOFAUTHORS}

- FR: prepared the protocol, uploaded the protocol in RevMan 5 and is the guarantor of this review.

- KMD: contributed to the review and discussion of the protocol.

- ML: contributed to the review and discussion of the protocol.

- CW: contributed to the review and discussion of the protocol.

- CR: contributed to the preparation, review and discussion of the protocol and provided statistical advice. .

- JG: contributed to the preparation, review and discussion of the protocol.

- CK: contributed to the review and discussion of the protocol.

\section{DECLARATIONSOF INTEREST}

- FR: none.

- KMD: author of a potentially eligible study. He is Co-Principal Investigator on the Prospective, personalised, comparison of ARni with ArB in patients with natriuretic peptide eLEvation (PARABLE) study, sponsored by Heartbeat Trust with unrestricted grant support from Novartis.

- ML: Prof Ledwidge reports board membership and shares in Solvotrin Therapeutics and H\&L Pharma and is a named inventor on several patents relating to isosorbide prodrugs of salicylates and iron-protein formulations. He is Co-Principal Investigator on the Prospective, personalised, comparison of ARni with ArB in patients with natriuretic peptide eLEvation (PARABLE) study, sponsored

Natriuretic peptide-guided treatment for the prevention of cardiovascular events in patients without heart failure (Protocol)

Copyright () 2018 The Cochrane Collaboration. Published by John Wiley \& Sons, Ltd. 
by Heartbeat Trust with unrestricted grant support from Novartis. He is funded by an EU FP7 grant investigating biomarkers of cardiovascular disease and a Health Research Board, Ireland, project grant. He is an author of a potentially eligible study.

- CW: author of a potentially eligible study.

- CR: none.

- JG: I have received consultancy fees from Novartis and payment for preparation of educational presentations by PCM Scientific Servier Laboratories and Novartis. I have received payment for talk preparation by Roche Diagnostics. I have received conference and travel fees from Servier, Novartis and Menarini. I am an author of a potentially eligible study.

- CK: none.

\section{SOURCES OF SUPPORT}

\section{Internal sources}

- No sources of support supplied

\section{External sources}

- The Cochrane Heart Group US Satellite is supported by intramural support from the Northwestern University Feinberg School of Medicine and the Northwestern University Clinical and Translational Science (NUCATS) Institute (UL1TR000150)., USA.

- This project was supported by the National Institute for Health Research, via Cochrane Infrastructure funding to the Heart Group. The views and opinions expressed therein are those of the authors and do not necessarily reflect those of the Systematic Reviews Programme, NIHR, NHS or the Department of Health, UK. 